\title{
Unilateral connation of permanent mandibular incisors: a case report
}

\begin{abstract}
Odontogenic anomalies can occur as a result of conjoining or twinning defects. Fusion and gemination are terms frequently used to describe the clinical presentation of connated teeth. The prevalence of connated teeth in the primary and permanent dentitions was found to be $0.4 \%$ to $0.9 \%$ and $0.2 \%$ respectively. Connation is even scarce in the mixed dentition. This article reports a rare case of unilateral connation of permanent mandibular left incisors in a 10 year old boy, associated with agenesis, confirmed by a radiographic presentation of a single root and single pulp canal of the effected teeth. Preventive measures like oral prophylaxis and sealant were placed on the connated teeth. Also the possible etiological factors along with differential diagnosis and future treatment options anticipated are discussed.
\end{abstract}

Keywords: connated teeth, double teeth, fusion, germination, tooth agenesis
Volume I Issue 5 - 2014

\author{
SVSG Nirmala, Sandeep Chilamakuri, \\ Sindhuri Veluru \\ Department of Pedodontics and Preventive Dentistry, Narayana \\ Dental College, India
}

\author{
Correspondence: SVSG Nirmala, Department of Pedodontics \\ and Preventive Dentistry, Narayana Dental College, Nellore, \\ Andhra Pradesh-524003, India, Tel 9440206976, \\ Email drnirmalavenkata@gmail.com
}

Received: August 21, 2014 | Published: October 13, 2014

\section{Introduction}

Connated teeth are the consequences of developmental anomalies leading to the eruption of joined elements. Fusion and gemination are terms frequently used to describe the clinical presentation of connated teeth. The terms 'double teeth', 'double formations', 'joined teeth', 'fused teeth' or 'dental twinning' are often used to describe fusion or gemination, both of which are primary developmental abnormalities of the teeth. It is caused by the persistence of the dental lamina between two or more tooth germs, or by the attempt of a supernumerary tooth to develop from the remnants of the dental lamina after it has divided from a neighbouring tooth germ. ${ }^{1}$ There are different clinical and radiographic appearances for connated teeth reliant on the developmental stages of the bud..$^{2}$ It is hypothesised that, forces or pressure can produce the contact between the teeth. Depending upon the stage of development, the union may be total or partial and may occur between a normal and a supernumerary tooth. ${ }^{3}$ Genetic inheritance can be considered as a possible etiology. ${ }^{1}$ The prevalence of connated teeth in the permanent dentition is approximately $0.2 \%{ }^{4}$ in the primary dentition it ranges from $04 \%{ }^{5}$ to $0.9 \%$.

It is accepted that fusion results from the conjoining of two tooth buds, while gemination occurs as a result of one tooth bud attempting to split into two. ${ }^{7}$ Radiographically, teeth with fusion will have two root canals with one or two roots, while geminated teeth has a single root and single canal. ${ }^{8}$ Clinically, the patient may present with a normal or a reduced number of teeth when associated with hypodontia in case of gemination. Conversely in the case of fusion, it will be one tooth less than normal in the affected arch. ${ }^{7}$ Geminated teeth are more common in the maxilla, while fused teeth occur more frequent in the mandible.

The present article describes a rare case of unilateral gemination of permanent mandibular incisors associated with agenesis. In addition review of literature along with possible treatment options were also presented.

\section{Case report}

A 10 year old boy reported to the Department of Pedodontics and Preventive Dentistry, Narayana Dental College, Nellore, Andhra Pradesh for routine dental check-up, presented with a large tooth in the lower left front region of the jaw (Figure 1). The boy was not concerned about the aesthetic appearance. The medical and family histories were not significant. Extraoral examination did not show any alterations. Intraoral examination revealed an early mixed dentition period with the presence of one large incisor that was abnormally wide on the left side of the lower arch (Figure 2 and 3). The child had 20 teeth and normal eruption pattern and occlusal status was evident. The double tooth presented a groove upto the cervical third of the crown and hypoplasia on the labial surface (Figure 4). Periapical radiograph displayed the connated incisor with a single root and single pulp canal (Figure 5). The orthopantomograph revealed the presence of double tooth along with the absence of lower left lateral incisor (Figure 6).

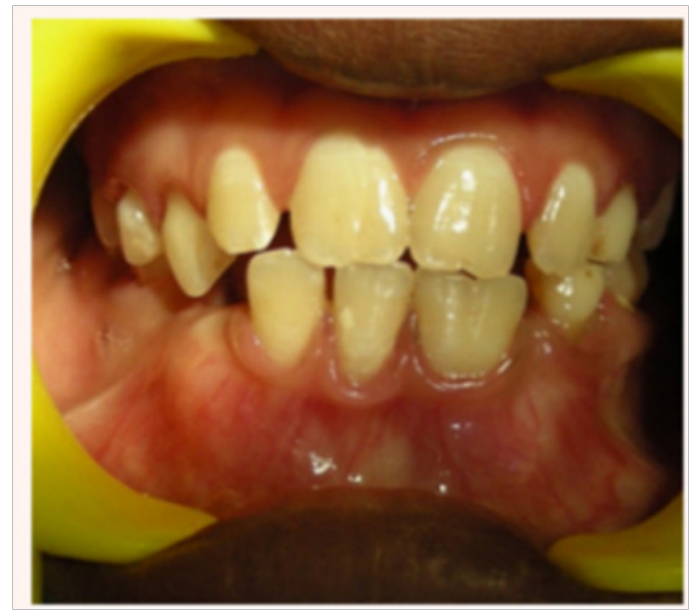

Figure I Intra oral picture showing teeth in occlusion.

Since double teeth pose an increased risk of dental caries as a result of local conditions that favour plaque accumulation in this area, appropriate management is necessary. Treatment considered was placement of a resin-based light-cured sealant on the groove in the centre and also on the labial surface of the double tooth.

\section{Discussion}

Connated teeth are the most common type of dental anomaly found in the primary dentition than in the permanent dentition. The 
use of Levitas classification to distinguish between cases of fusion and gemination is very practical. ${ }^{10}$ Counting the number of teeth in the $\operatorname{arch}^{11,12}$ or observing the root morphology ${ }^{13}$ are also considered. It is difficult to diagnose based on the number of teeth because nothing impairs the fusion between a normal and supernumerary teeth while the contiguous normal tooth is congenitally absent, resembling clinical cases of germination. ${ }^{14}$ It is very difficult to distinguish the differences between them if they don't have clinical relevance. ${ }^{15}$ Sometimes both fusion and germination are used as 'synonyms" ${ }^{16,17}$ or simply as 'connated teeth' ${ }^{18}$ or 'double teeth'. ${ }^{19}$

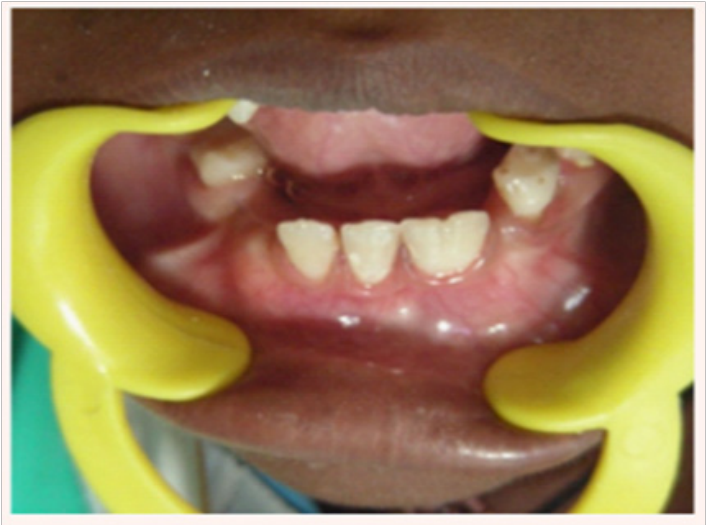

Figure 2 The mandibular arch showing the connated tooth.

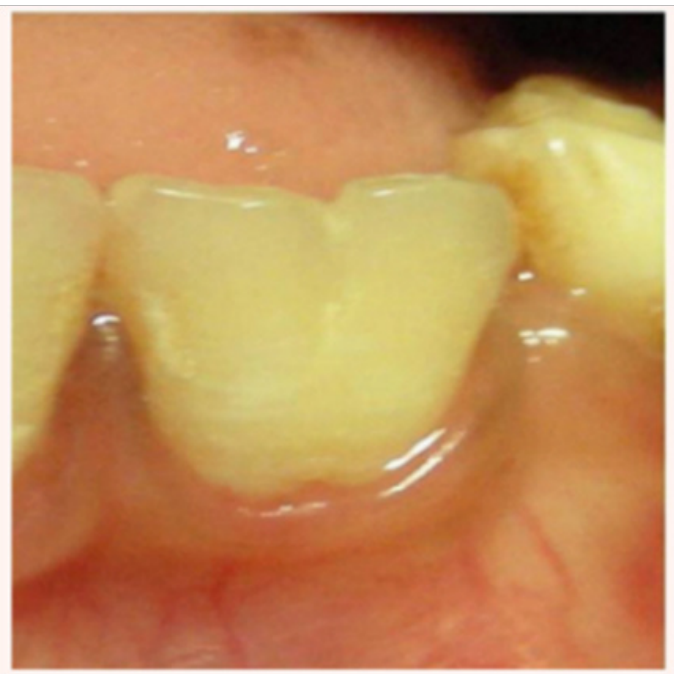

Figure 3 Close up view of connated teeth showing a groove that extends upto the cervical third of the crown.

The case presented could be considered typical, showing clinical characteristics of gemination of 31 and agenesis of 32 . The radiographic appearance of single root and single pulp canal and the presence of one tooth less on the left side of the lower arch confirmed the diagnosis. This could be related to attempted splitting of the tooth bud in 31 and congenitally missing bud in 32 regions. Tooth agenesis is one of the most common craniofacial malformations of the permanent dentition with $20 \%$ prevalence. Kolenc-Fuse ${ }^{20}$ observed that mutations were responsible for some patterns of tooth agenesis.

If the connated tooth is considered as a case of fusion because of typical clinical appearance of large tooth and one tooth less in the arch, this opinion can be discarded after observing the root morphology. ${ }^{13}$ There is extensive literature on the occurrence of double teeth. Nik-
Hussein and Abdul Majid ${ }^{21}$ analysed 65 children with dental anomalies in the primary dentition and noted $75 \%$ cases with double teeth, $94 \%$ were fusion and $6 \%$ were gemination. The anomalies of permanent dentition are strongly associated with that of the primary dentition. They also stated that the presence of double teeth in primary dentition is associated with anomalies in $60 \%$ of cases. Brook and Winter ${ }^{9}$ reported that half of the primary double teeth have an anomaly in the permanent dentition.

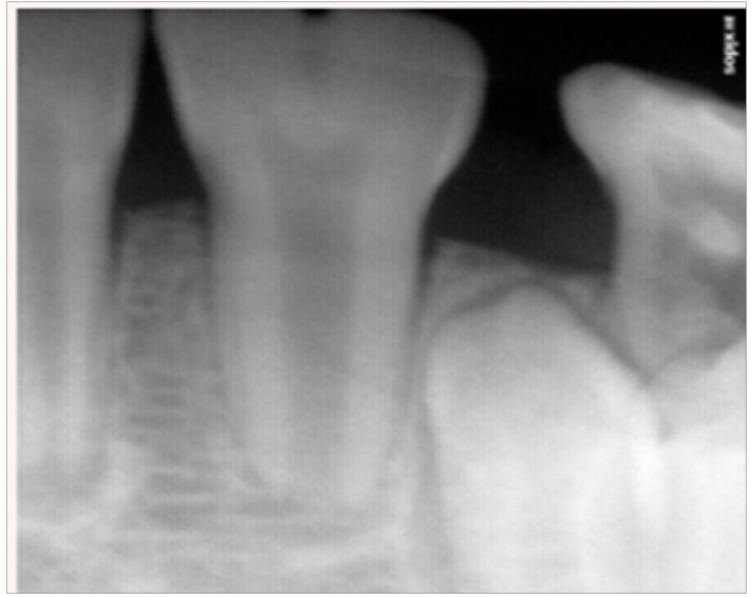

Figure 4 Periapical radiograph showed that the connated incisor had a single root and single pulp canal and absence of permanent lateral incisor tooth bud.

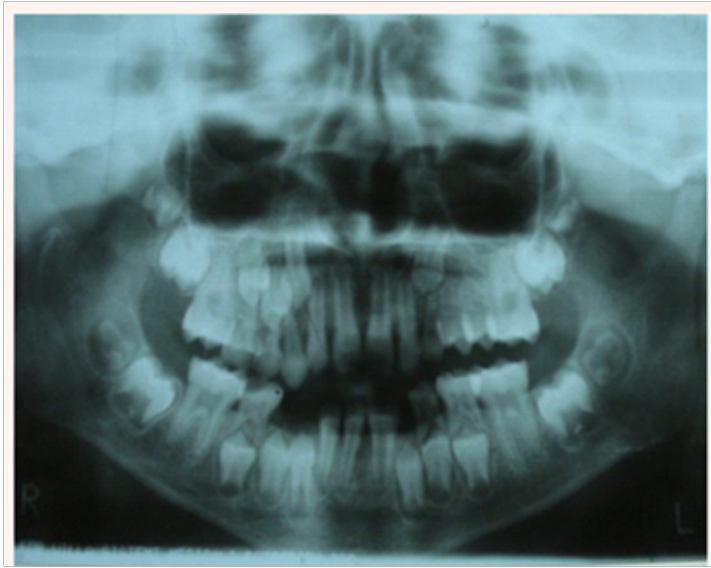

Figure 5 Panoramic radiograph revealed the presence of double teeth and the absence of lower left lateral incisor.

Cases of unilateral fusion of permanent mandibular incisors were also reported. Aguilo et al. ${ }^{22}$ showed that double teeth were mostly unilateral, involving two adjacent teeth, and no difference in their occurrence either in the maxilla or mandible, or on the left or right sides. Chaudhry et al. ${ }^{7}$ concluded that the dental twinning anomalies influence tooth alignment and interdigitation, arch asymmetry, appearance, and associated periodontal problems.

Double teeth may lead to serious problems relating to aesthetics and malocclusion, especially when involving supernumerary elements, ${ }^{23}$ or the presence of carious lesions along the grooves dividing the crown. ${ }^{24}$ It may also be associated with plaque accumulation which in turn leads to gingival and periodontal problems. In the present case, the child was asymptomatic and as aesthetics was not impaired in this case, the dental treatment was aimed towards instructions on proper oral hygiene measures to prevent plaque accumulation in risk areas and sealant placement alone was done. Separation of the double teeth is not indicated as the pulp canals are united. 
The treatment varies depending upon the signs and symptoms which involves oral hygiene maintenance, esthetic restorations, endodontic therapy followed by full coronal restoration, orthodontic therapy and even extraction followed by prosthetic replacements including implants. In conditions where the pulp and canals are separated, diverse modes of treatments have been suggested including, separation and extraction of the anomalous tooth with orthodontic closing of the space followed by reshaping of the teeth, surgical separation and restoration of remaining tooth structure, selective grinding of the connated tooth to reduce the crown width. When aesthetics is the prime concern and where there is no underlying risk factors associated, reshaping of the crown with various materials like, direct composite bonding, bonded porcelain veneers, and crowns have been suggested.

There is also a case report illustrating extraction of a fused maxillary central incisor and mesiodens, where the teeth were separated and finally, reimplanted the central incisor. Advanced treatments options include sectioning and restoration, reconstruction with metalloplastic crown, amputation of one root, which greatly depend on location and extent of fusion.

\section{Conclusion}

It is very important to confirm the diagnosis by appropriate radiographs to identify the anomaly and organize a conservative individualized treatment plan, including endodontic, ${ }^{25}$ conservative, prosthodontic, periodontal and orthodontic considerations, when required. ${ }^{12}$ Also accurate assessment of the patient's expectations and degree of compliance is determined for proper management. Recognizing the condition will facilitate the establishment of appropriate treatment plan with multidisciplinary approach.

\section{Acknowledgments}

None.

\section{Conflicts of Interest}

There is no conflict of interest.

\section{Funding}

None.

\section{References}

1. Hitchin AD, Morris I. Geminated odontome: connation of the incisors in the dog, its etiology and ontology. J Dent Res. 1996;45:575-83.

2. Tannenbaum KA, Alling EE. Anomalous tooth development: Case reports of gemination and twinning. Oral Surgery, Oral Medicine, Oral Pathology. 1963;16(7):883-887.

3. Shafer WG, Hine I, Levy BM. A textbook of Oral Pathology. 4th edn W.B. Saunders Company, Toranto, USA. 1987; p. 2-79.

4. Grover PS, Carpenter WM, Allen GW. Panographic survey of US army recruits: analysis of dental health status. Mil Med. 1982;147(12):10591061
5. Buenviaje TM, Rapp R. Dental anomalies in children: a clinical and radiographic survey. ASDC J Dent Child. 1984;51(1):42-46.

6. Curzon JA, Curzon ME. Congenital dental anomalies in a group of British Columbia children. J Can Dent Assoc (Tor). 1967;33(10):554 558

7. Chaudhry SI, Sprawson NJ, Howe L, et al. Dental twinning. Br Dent $J$. 1997;182(5):185-188.

8. Boyne PJ. Gemination; report of two cases. J Am Dent Assoc. 1955;50(2):194.

9. Brook AH, Winter GB. Double teeth. A retrospective study of 'geminated' and 'fused' teeth in children. Br Dent J. 1970;129(3): 123-130.

10. Levitas TC. Gemination, fusion, twining and concrescence. ASDC J Dent Child. 1965;32:93-100.

11. Peretz B, Brezniak N. Fusion of primary mandibular teeth: report of case. ASDC J Dent Child. 1992;59(5):366-368.

12. Serrano J . Bilateral fusion of teeth. Oral Surg Oral Med Oral Pathol. 1972;34(2):348-349.

13. Camm JH, Wood AJ. Gemination, fusion and supernumerary tooth in the primary dentition: report of case. ASDC J Dent Child. 1989;56(1):60-61.

14. Kelly JR. Gemination, fusion, or both? Oral Surg Oral Med Oral Path. 1978;45(2):326-327.

15. Pereira AJ, Fidel RA, Fidel SR. Maxillary lateral incisor with two root canals: fusion, gemination or dens invaginatus. Braz Dent J. 2000;11(2):141-146.

16. Munro D. Gemination in the deciduous dentition: report of 31 cases. $\mathrm{Br}$ Dent J. 1958;104:238-240.

17. O'Reilly PMR. Structural and radiographic evaluation of four cases of tooth fusion. Aust Dent J. 1990;35(3):226-229.

18. MacCallum WD. Bilateral connate incisors: a case report. $\mathrm{Br}$ Dent $J$. 1968;124(9):405-406

19. Itkin AB, Barr GS. Comprehensive management of the double tooth: report of case. J Am Dent Assoc. 1975;90(6):1269-1272.

20. Kolenc-Fuse FJ. Tooth agenesis: in search of mutations behind failed dental development. Med Oral Patol Oral Cir Bucal. 2004;9(5):385390.

21. Nik-Hussein NN, Abdul Majid Z. Dental anomalies in the primary dentition: distribution and correlation with the permanent dentition. $J$ Clin Pediatr Dent. 1996;21(1):15-19.

22. Aguilo L, Gandia JL, Cibrian R, et al. Primary double teeth. A retrospective clinical study of their morphological characteristics and associated anomalies. Int J Paediatr Dent. 1999;9(3):175-183.

23. Clem WH, Natkin E. Treatment of the fused tooth. Report of a case. Oral Surg Oral Med Oral Pathol. 1996;21(3):365-370.

24. Surmont PA, Martens LC, DeCraene LG. A complete fusion in the primary human dentition: a histological approach. ASDC J Dent Child. 1988;55(5):362-367.

25. Santos LM, Forte FD, Rocha MJ. Pulp therapy in a maxillary fused primary central incisor: report of a case. Int $J$ Paediatr Dent. 2003;13(4):274-278. 